\title{
European plant phenology and climate as seen in a 20-year AVHRR land-surface parameter dataset
}

\author{
R. STÖCKLI* and P. L. VIDALE \\ Institute for Atmospheric and Climate Science, ETH, Winterthurerstrasse 190, \\ 8057 Zurich, Switzerland
}

(Received 9 September 2002; in final form 26 May 2003)

\begin{abstract}
Vegetation distribution and state have been measured since 1981 by the AVHRR (Advanced Very High Resolution Radiometer) instrument through satellite remote sensing. In this study a correction method is applied to the Pathfinder NDVI (Normalized Difference Vegetation Index) data to create a continuous European vegetation phenology dataset of a 10-day temporal and $0.1^{\circ}$ spatial resolution; additionally, land surface parameters for use in biosphere-atmosphere modelling are derived. The analysis of time-series from this dataset reveals, for the years 1982-2001, strong seasonal and interannual variability in European land surface vegetation state. Phenological metrics indicate a late and short growing season for the years 1985-1987, in addition to early and prolonged activity in the years 1989, 1990, 1994 and 1995. These variations are in close agreement with findings from phenological measurements at the surface; spring phenology is also shown to correlate particularly well with anomalies in winter temperature and winter North Atlantic Oscillation (NAO) index. Nevertheless, phenological metrics, which display considerable regional differences, could only be determined for vegetation with a seasonal behaviour. Trends in the phenological phases reveal a general shift to earlier $\left(-0.54\right.$ days year $\left.^{-1}\right)$ and prolonged $\left(0.96\right.$ days year $\left.^{-1}\right)$ growing periods which are statistically significant, especially for central Europe.
\end{abstract}

\section{Introduction}

Interactions between the land surface and the atmosphere include turbulent heat, moisture, momentum and carbon exchanges, which can largely determine the state of climate and its variations in the near-surface continental climate (Chen et al. 2001, Pielke 2001). In addition, vegetation physiology and phenology are very sensitive to climate forcings through several feedback mechanisms at various timescales (Bounoua et al. 1999). It is well known, for instance, that plants assimilate carbon in the process of photosynthesis, while losing water through transpiration (Sellers et al. 1997): the terrestrial water and carbon cycles are closely linked by these processes. Keeling et al. (1996) examined $\mathrm{CO}_{2}$ records from the Mauna Loa station from 1964 to 1994 and found that amplitudes in the yearly $\mathrm{CO}_{2}$ cycle (linked to vegetation activity) increased by $20 \%$. They attributed those trends

\footnotetext{
*Corresponding author; e-mail: stockli@env.ethz.ch
} 
to increased assimilation by land vegetation, associated with anthropogenic global climate change.

The timing of phenological events is affected by naturally changing local environmental conditions as well as by biogeochemical factors like diseases, soil moisture, nutrients and age of the individual plants (Menzel 2000). Many phenological phases used in biometeorology, such as leaf unfolding and leaf colouring, are primarily driven by local climatic conditions, like temperature and snow cover during winter and early spring. Ground-measured vegetation phenology has been studied since the 18th century (Menzel 2000, Roetzer et al. 2000, Defila 2001): data from International Phenological Gardens (IPG) from 1959 to 1996 and from wild plants in Switzerland, show high sensitivity of vegetation dynamics to interannual climate variations. These studies have recently been linked to the observed global warming. Phenological events in spring are known to be especially sensitive to climatic influences: in the IPG phenological records springs have advanced over 6.3 days and autumn has been delayed by 4.5 days since the early $1960 \mathrm{~s}$.

The variability of vegetation state and function motivates the creation of highresolution vegetation parameters varying dynamically over space and time. These parameters can be used to model the complex soil-vegetation-atmosphere interactions but also to assess the long-term changes in land use and vegetation physiology over a large area. During the last two decades many efforts have been made to better integrate land surface processes in climate modelling: Sellers et al. 1997 and more recently Pielke 2001 provide thorough reviews of land surface models used in climate research. These mathematical formulations have evolved during the last two decades from simple abiotic relationships, e.g. the bucket model (Manabe 1969), to sophisticated biogeochemical models like Simple Biosphere Model (SiB) 2 (Sellers et al. 1996a) and Land Surface Model (LSM) (Bonan 1996), which include a treatment of leaf photosynthesis and $\mathrm{CO}_{2}$ exchange. While it is possible to derive biophysical vegetation parameters for use in these models from existing land cover surveys, published in the form of maps (Matthews 1983, DeFries et al. 1998, Hansen et al. 2000, Loveland et al. 2000), this approach accounts exclusively for spatial variability, neglecting temporal variability. The knowledge of temporal variability of vegetation function is, however, a key issue to meet the requirements of the United Nations Framework Convention on Climate Change (UNFCCC) and the Kyoto Protocol, in order to quantify the carbon pools and exchanges on local and on global scale.

The knowledge of vegetation phenology for entire ecosystems and on global scale has thus in past decades been limited, either in space or in time. In comparison to the ground-based global vegetation classifications by Matthews (1983) and Wilson and Henderson-Sellers (1985), satellite remote sensing now offers the possibility to estimate vegetation phenology on the global scale with a high temporal frequency. Since the 1980s multi-spectral satellite observations from the National Oceanic and Atmospheric Administration's (NOAA) Polar Orbiting Environmental Satellites (POES) provide daily global coverage datasets of visible and near-infrared surface reflectances. From those, the Normalized Difference Vegetation Index (NDVI) can be derived as has been shown by Justice et al. (1985), Tucker and Sellers (1986), Reed et al. (1994), Voivy and Saint (1994), Myneni et al. (1997), Champeaux et al. (2000), Los et al. (2001) and Zhou et al. (2001). The NDVI exploits the spectral properties of green plant leaves and is an estimator for the radiation used within the photosynthesis process occurring in leaves. Asrar et al. (1985), Tucker and Sellers (1986), Sellers et al. (1996b) and Los (1998) showed that 
the temporal evolution of the Fraction of Photosynthetically Active Radiation absorbed by the green leaves (FPAR), the Leaf Area Index (LAI) and other biophysical vegetation parameters can be estimated empirically from NDVI with the use of land cover type dependent vegetation constants. Sets of land surface parameters can be found of low resolution and global scale in the ISLSCP dataset collection (Meeson et al. 1995) for the years 1987/1988, extended by Los et al. (2000) for the 9-year period 1982-1990.

Satellite sensor data can also provide a good means to verify trends of ground observed vegetation activity. Myneni et al. (1997) have investigated the 1981-1991 Advanced Very High Resolution Radiometer (AVHRR) NDVI record from the GIMMS and the Pathfinder dataset for the northern hemisphere. They have detected an advance in the active growing season of $8 \pm 3$ days and a delay in the declining phase of $4 \pm 2$ days over this decade. Zhou et al. (2001) looked at the northern hemisphere vegetation activity derived from AVHRR NDVI and land surface temperature records during 1981-1998 and found an increase in mean NDVI for Eurasia and North America.

Remote sensing of land surface properties is, however, a complex and problematic task. Atmospheric absorption and scattering by gas molecules and aerosols, persistent cloud cover, viewing geometry effects, illumination conditions and technical difficulties limit the use of these satellite measurements. Much research has been accomplished in the last two decades in order to correct and calibrate multi-temporal NDVI data (Tucker and Matson 1985, Holben 1986, Goward et al. 1991, Gutman and Ignatov 1995, Cihlar et al. 1994, Sellers et al. 1996b, Los 1998, Los et al. 2000).

In this study we use the highly processed NOAA/NASA Pathfinder NDVI dataset, which is already corrected for many of the problems mentioned above. From the Pathfinder NDVI a continuous 20-year vegetation phenology dataset is extracted and biophysical land surface parameters covering the period from 1982 to 2001 are derived with high spatial and temporal resolution. We focus on Europe and study regional variability seen in vegetation dynamics. The methodology involves the use of a refined correction algorithm based on Los et al. (2000) to extract the vegetation phenology from satellite sensor data. Long-term surface observations in both phenology and climate over continental Europe make it possible to conduct meaningful statistical intercomparisons and this offers the opportunity to further validate the soundness and usefulness of these land surface products. Inter-annual variability and regional differences in phenology in particular have not been analysed previously at this spatial and temporal scale over this region.

In $\S 2$ the methodology used to derive the set land surface parameters from the NASA/NOAA Pathfinder NDVI is presented. An analysis of interannual and seasonal variation of these land surface parameters is presented in the Results in $\S 3$. The relationship between interannual climate anomalies and vegetation phenology are examined for a number of European sub-domains. A discussion of the results follows in $\S 4$.

\section{Data and methodology}

\subsection{Pathfinder NDVI}

The NDVI exploits the spectral properties of green plant leaves, which absorb incoming radiation in the visible part of the spectrum (AVHRR red channel: $0.62-0.7 \mu \mathrm{m}$ ) and strongly reflect light in the near-infrared wavelengths (AVHRR NIR channel: $0.74-1.1 \mu \mathrm{m}$ ). This ratio has low values ranging from -0.2 to +0.1 
for snow, bare soil, glaciers, rocks and rises to around $0.2-0.8$ for green vegetation. NDVI is an estimator for the radiation used within the photosynthetic processes occurring in leaves.

For the derivation of the 1982-2001 biophysical surface parameters we used the NOAA/NASA Pathfinder NDVI dataset (James and Kalluri 1994). The data are collected by the AVHRR instrument onboard the NOAA POES platforms. These operational satellites are successively replaced at failure and are supposed to provide a continuous and consistent data record into the future. The Pathfinder NDVI dataset is corrected for Rayleigh scattering by applying the radiative transfer model by Gordon et al. (1988). Ozone absorption in the signal is removed by the estimation of the atmospheric ozone column from daily TOMS (Total Ozone Mapping Spectrometer) measurements. Each satellite (NOAA 7, 9, 11 and 14-only the 'afternoon' overpass satellites were used by the Pathfinder project) flown during the period 1981 to present has been subject to instrumental degradation during the operational period, which was accounted for by fitting a time-dependent calibration algorithm (Rao and Chen 1996) for each individual channel. The NDVI is calculated from the AVHRR channel 1 visible (VIS) and channel 2 near-infrared (NIR) reflectances by taking the ratio

$$
\mathrm{NDVI}=\frac{\mathrm{NIR}-\mathrm{VIS}}{\mathrm{NIR}+\mathrm{VIS}}
$$

Within the Pathfinder NDVI dataset these daily swath data are geolocated and gridded at $8 \mathrm{~km}$ resolution and composited over 10-day periods with the maximum value composite (MVC) algorithm (Holben 1986) to a global coverage. The dataset is not corrected for aerosols (for instants volcanic eruptions such as Mt Pinatubo in June 1991 or smoke from forest fires), water vapour absorption and illumination and viewing geometry effects. Some of these disturbances are compensated in the NDVI since it is basically a ratio between two spectral bands. Zhou et al. (2001) assess the effect of the solar zenith angle to NDVI as weak, especially in seasonal and inter-annual terms. An average registration error of $6 \mathrm{~km}$ was observed by Holben (1986) in the geolocated AVHRR data. Prior to any corrections, an overall absolute error in the NDVI in the order of 0.1-0.2 must be considered (Los 1998).

The lack of a good pre-calibration in the AVHRR Pathfinder NDVI dataset is problematic for the derivation of spatio-temporally consistent land surface parameters. For the generation of the 10-day composites the cloud mask is not used. Also, anomalously high data values (NDVI >0.8) are found and pixels with high solar zenith angles are set to missing data values. Yearly time-series of the NOAA Pathfinder NDVI for various areas and years are found in figure 1 (thin solid lines) and show some of the inconsistencies. More sophisticated atmospheric correction schemes are used for the MODIS (MODerate resolution Imaging Spectroradiometer) data processing (see, for example, Vermote et al. 1997).

The current in-operation POES afternoon satellite NOAA-14 is consistently drifting westwards, which leads to a later equatorial overpass. In figure 2 time-series of NDVI for the years 1981-2001 are shown. Over the Sahara desert (figure 2(a)) the higher solar zenith and instrument angles leads to a decreasing NDVI signal beginning in late 2000. For vegetated areas this effect is partly compensated as this can be seen in figure $2(b)$, but the degradation of the satellite signal is problematic for our application, since northern Europe will have larger data dropouts during winter time. The NASA DAAC does not recommend using the newest 2001 Pathfinder data for scientific purposes (http://daac.gsfc.nasa.gov/ 

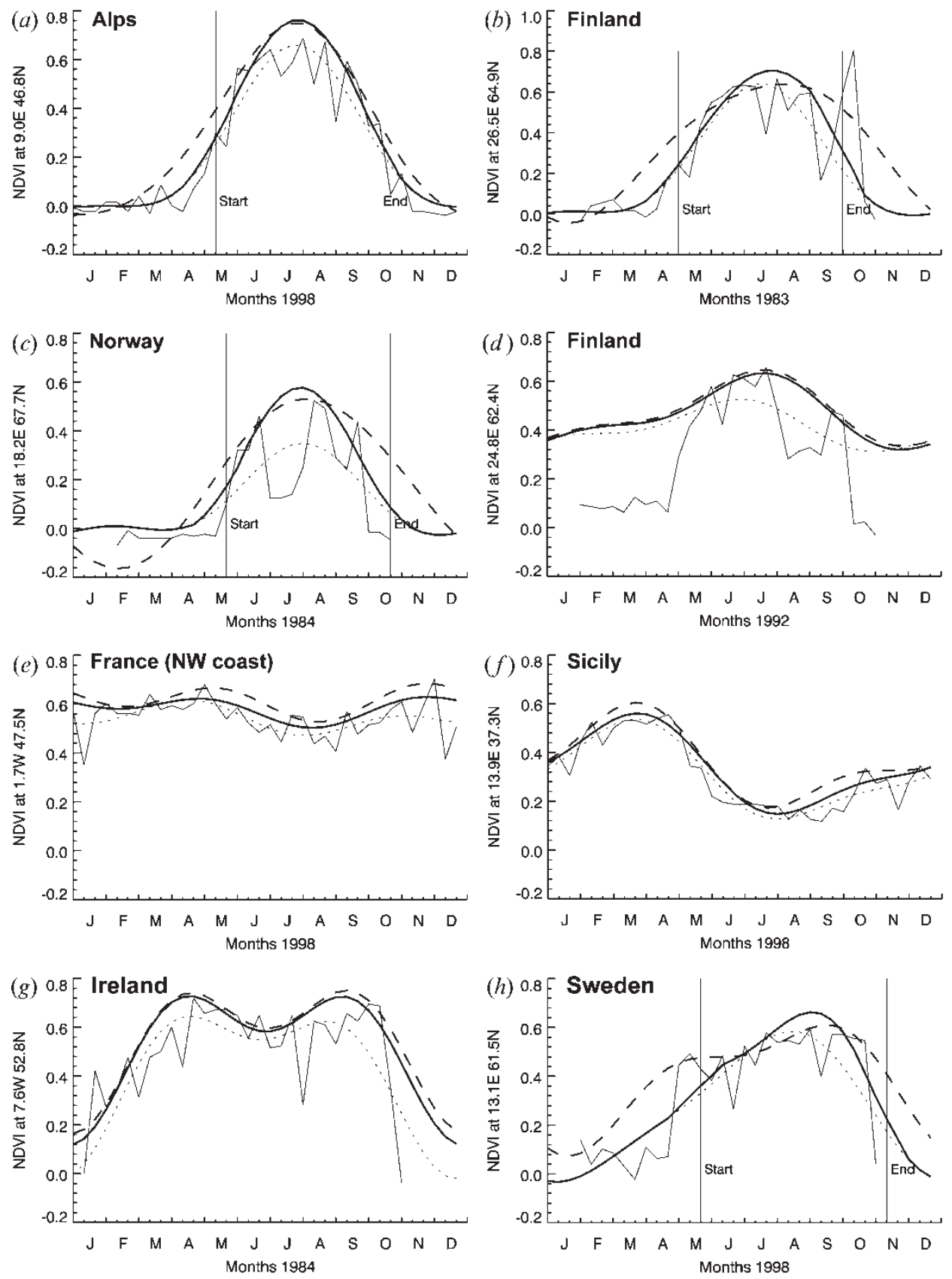

Figure 1. Pathfinder NDVI time-series (thin solid), Fourier adjusted with an unweighted scheme (dotted), weighted after Sellers et al. (1996b) (dashed) and with the EFAINDVI method discussed in this paper (thick solid). (a) Swiss Alps, (b) Finland, (c) Norway, $(d)$ Finland, $(e)$ north-west France, $(f)$ Sicily, $(g)$ Ireland, and $(h)$ Sweden.

CAMPAIGN_DOCS/LAND_BIO/AVHRR_News.html) and has stopped producing the dataset on a regular basis by September 2001. A new generation of sensors like MODIS (launched onboard the TERRA satellite in 1999 and onboard the AQUA satellite in 2002) can provide land surface data for this time period. 

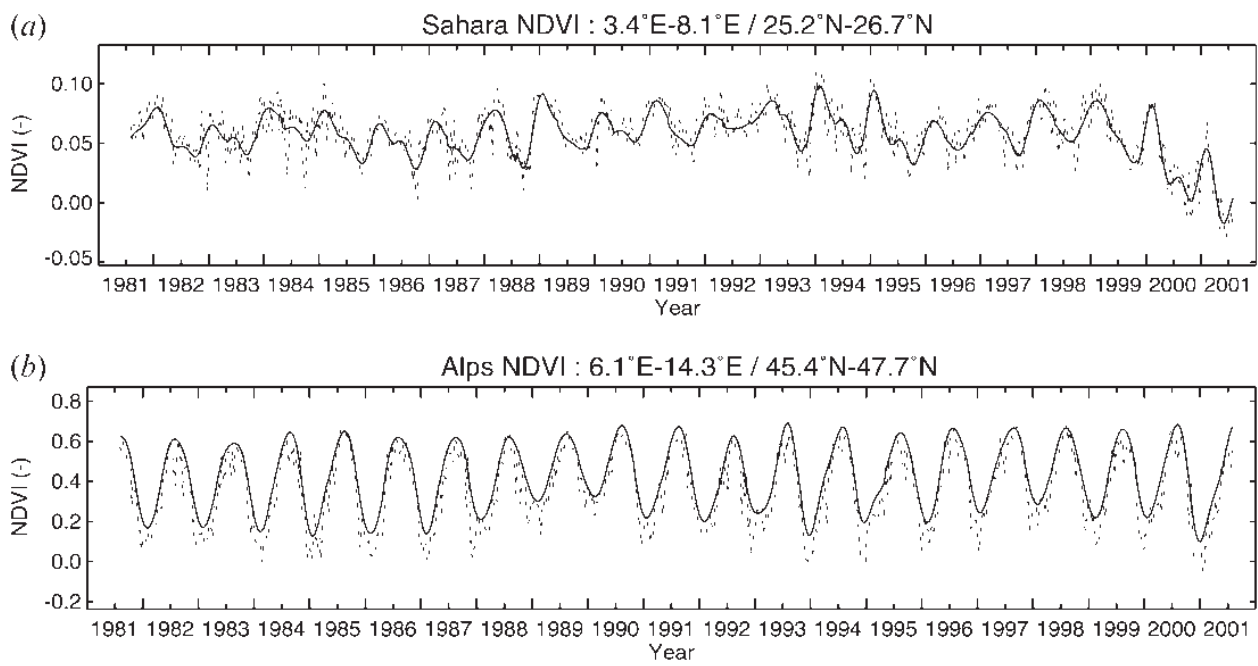

Figure 2. Twenty-year NDVI time-series for a grid point in (a) the Sahara and (b) the Alps. The dashed line shows the original Pathfinder NDVI, and the solid line represents the corrected EFAI-NDVI phenology time-series.

\subsection{Correction methodology}

To create a consistent dataset of vegetation phenology, we analyse and correct yearly time-series of Pathfinder NDVI over the European continent at a 10-day temporal and $0.1^{\circ}$ spatial grid for the period from 1982 to 2001 . Two steps are involved in the spatio-temporal interpolation process: (1) replacement of processing artefacts and no-data values in the dataset by spatial interpolation (\$2.3.); and (2) adjustment of the NDVI time-series by using a temporal interpolation procedure (\$2.4.).

The following three assumptions can be made when extracting time-series of the state of land surface vegetation from the error-contaminated satellite remotely sensed NDVI:

- The vegetation phenology follows a repetitive seasonal cycle (Moulin et al. 1997) and NDVI values vary smoothly with time (Sellers et al. 1996b).

- During the summer, outliers in NDVI time-series are the result of either cloud cover or atmospheric disturbances. These effects tend to decrease NDVI values (Holben 1986, Los 1998).

- During the winter, snow under or temporarily on the canopy may impose a negative bias on the NDVI signal, since snow has a high VIS reflectance and a low NIR reflectance.

These assumptions lead to the application of a Fourier adjustment algorithm described in Sellers et al. (1996b) and Los (1998). The second-order Fourier series are able to represent the seasonal variability of vegetation phenology with a smooth analytical function and the original data can be weighted so that higher NDVI values representing uncontaminated measurements receive higher weights than negative outliers (which are attributed to erroneous measurements). This technique was applied successfully to produce the FASIR-NDVI (Fourier Adjustment, Solar zenith angle, correction, Interpolation and Reconstruction) published in the ISLSCP dataset collection (Meeson et al. 1995) at a monthly temporal and $1^{\circ}$ spatial scale. The following sections present the modifications brought to the Sellers et al. (1996b) 
and Los (1998) approach in order to create the new $0.1^{\circ}$ and 10-day EFAI-NDVI (European Fourier-Adjusted and Interpolated NDVI) dataset.

\subsection{Spatial interpolation}

In comparison to the ISLSCP FASIR-NDVI the present dataset is of a much higher spatio-temporal resolution and therefore small area inconsistencies in the dataset are well visible. We have applied a spatial interpolation prior to extracting the yearly phenology curves from the NDVI time-series. No-data values in high latitude biomes during winter are set to a minimum NDVI value as it is a prerequisite for the correct functioning of the temporal interpolation described in $\$ 2.4$.

To remove the most predominant artefacts all NDVI values above 0.8 are set to missing data. A second-order Fourier series, $f$, is fitted to the yearly Pathfinder NDVI time-series at each grid point. Anomalous NDVI values are detected and flagged as missing if they were outside the boundary $(0.8 f-0.2)<\mathrm{NDVI}<(1.2 f+0.2)$ of this 'idealized' phenology curve $f$. Missing data are spatially interpolated for each 10-day interval according to the following technique, which is an inverse-distance weighted interpolation. For each missing grid point valid neighbours of the same land cover class within a radius $r$ are sampled. The missing value is then replaced by an inverse distance weighted mean of these valid neighbours:

$$
\begin{gathered}
W_{i}=\frac{1}{\sqrt{x_{i}^{2}+y_{i}^{2}}} \\
\mathrm{NDVI}=\frac{\sum W_{i} N_{i}}{\sum W_{i}}
\end{gathered}
$$

where $W_{i}=$ weight of a valid neighbour $N_{i}, x_{i}=$ horizontal distance of neighbour $N_{i}$ to the missing value, $y_{i}=$ vertical distance of neighbour $N_{i}$ to the missing value, $N_{i}=$ valid neighbouring NDVI, same land cover class as the missing NDVI value.

Missing data in high latitudes during winter time do occur in an extended area and cannot be interpolated by the above described method. They are flagged when missing data are found for successively five or more 10-day intervals during winter for an individual grid point. Using a land cover map (DeFries et al. 1998) these prolonged periods of missing data are replaced differently for deciduous and for evergreen vegetation. During winter deciduous vegetation is assumed to be in a dormant state and the canopy may be masked by snow cover. These grid points are assigned to a NDVI value of -0.05 . Boreal conifers found in Sweden, Finland and the former Soviet Union keep their needles during winter. They project out of the snow layer and these areas have a low albedo during winter (Betts and Ball 1997). All NDVI values for evergreen forests, which are lower than 0.25 are replaced by the mean of the four last valid NDVI values in late autumn (mostly October values). The underlying assumption of this method holds when NDVI for evergreen forests does not drop below the chosen threshold and if by the end of the vegetation period all deciduous plants have shed their leaves (Sellers et al. 1996b).

Spatial error detection and interpolation is applied to all of the 10-day Pathfinder datasets over the European domain ranging from August 1981 until July 2001.

\subsection{Temporal interpolation}

The production of NDVI-derived biophysical parameters, used in LSMs to drive the yearly evolution of land surface vegetation, requires that for each grid 
point they are consistent over time and represent the actual area-averaged state of vegetation. According to the three assumptions presented at the beginning of this section the second order Fourier series are used to extract the seasonal varying phenology time-series from the spatially interpolated NDVI dataset. The Fourier adjustment technique performs well, as described in Sellers et al. (1996b) and Los (1998). We evaluate the Fourier adjustment algorithm by first working with theoretical time-series of simulated yearly NDVI curves including artificial data gaps. In figure 3 we compare the use of 10-day intervals (36 yearly data values) to monthly time-steps. The use of 10-day intervals enhances the ability of the Fourier adjustment to reproduce the simulated phenological curve, even when 2 months of data are flagged as missing. In figure $3(b)$ the reconstructed curve has a better fit to the original curve with $R^{2}=0.994$ for 10-day intervals than for a monthly dataset (figure $3(a), R^{2}=0.922$ ). Especially during the start and the end of the active growing period the temporal resolution seems to be an important factor.

Nevertheless, the original Fourier adjustment algorithm as first described by Sellers et al. (1996b) has several shortcomings when used with the $0.1^{\circ}$ and 10 -day Pathfinder NDVI. Biomes with a short growing season have a steep increase in
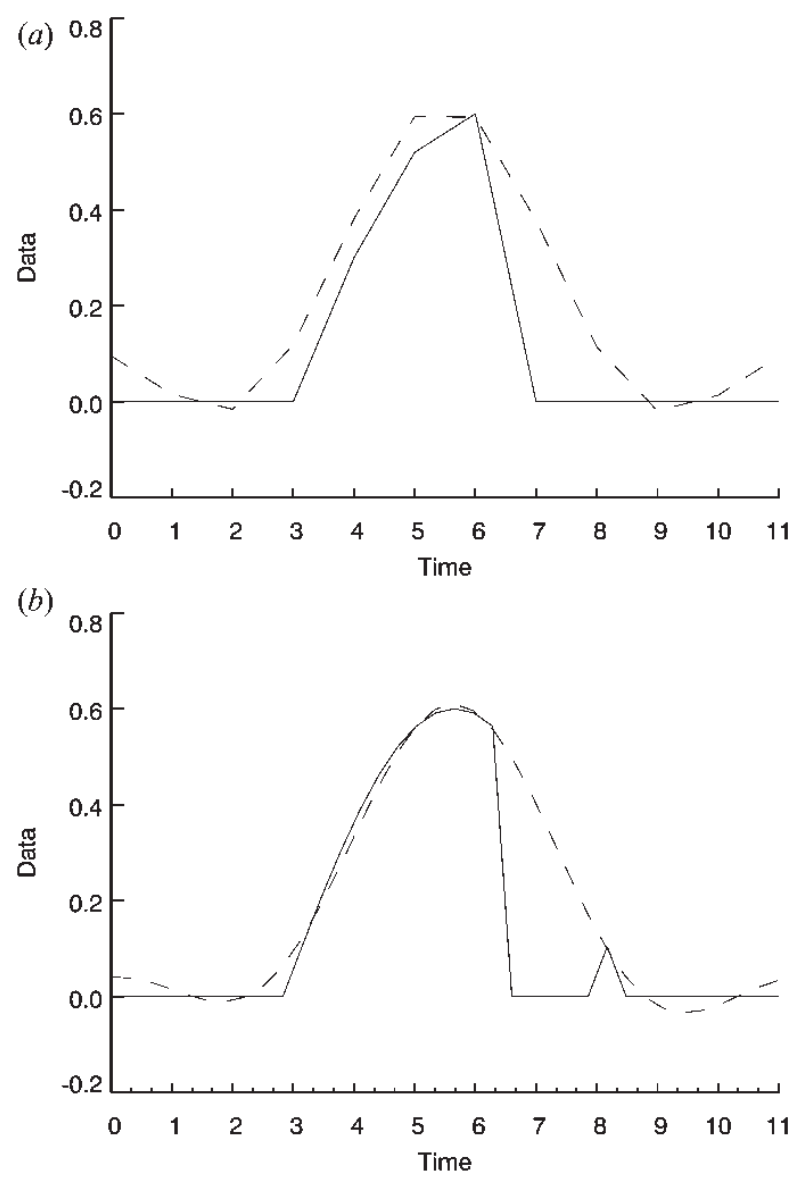

Figure 3. Theoretical phenology time-series: $(a) 12$ and (b) 36 data values per year. The solid line represents the modelled NDVI time-series with a 2-month long gap period where a discrete Fourier time-series (dashed) was fitted. 
photosynthetic activity in late spring due to leaf unfolding and snowmelt and are subject to a rapid decrease in NDVI when they shed their leaves in autumn. Only a short period of greenness is observed for those biomes (high latitude deciduous forest and biomes in mountainous regions). Second-order Fourier series are able to represent features of a half-year periodicity and cannot account for such fast processes. As a result, the state of vegetation can be overestimated by the Fourier adjustment at the beginning and at the end of the growing season and in some cases a second peak is simulated in late winter. The Fourier adjustment algorithm is developed for spatially and temporally subsampled data at the $1^{\circ} \times 1^{\circ}$ level and works well with that configuration. The present dataset is at a much finer resolution and includes local-scale variability and short term features (e.g. leaf-out in spring) due to the used 10-day interval.

The ideas developed by Sellers et al. (1996b) and Los (1998) are revised for our purposes and only modifications to these algorithms presented here. For each grid point, yearly NDVI time-series are processed in the following way:

1. Each yearly time-series is tested for a summertime growing season. The temporal derivative of a fitted second-order Fourier series is examined for each year at each pixel. A growing season is detected if the maximum $/$ minimum derivative of this modelled curve $f$ exceeds $0.03 /-0.03$ for the start/end of the growing season (corresponding to an increase/decrease of 0.03 (NDVI) per 10 days). The actual start/end dates of the growing season is then shifted one 10-day period to the beginning/end of the year to be on the safe side. Only deciduous vegetation classes are tested for a growing season.

2. For vegetation with a continuous transition between the growing/nongrowing period (e.g. evergreen biomes) we apply the weighted Fourier adjustment procedure proposed by Los (1998) with a slightly modified weighting function. This new weighting function is shown in figure 4 and does prevent excessive weights for large positive anomalies in the time-series.

$$
W=\left\{\begin{array}{l}
\left(\frac{(d-t)}{-t}\right)^{4}, t<d<0 \\
4 \sqrt{d}+1, d \geqslant 0
\end{array}\right.
$$

where $t=-0.1, d=N D V I-f, N D V I=$ spatially corrected NDVI values, $f=$ secondorder discrete Fourier series of NDVI, and $W=$ weights

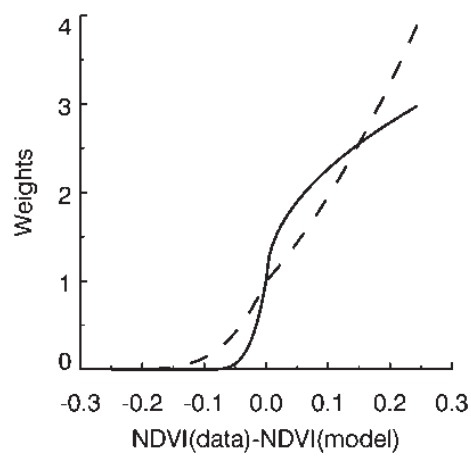

Figure 4. Weighting scheme used for the weighted Fourier adjustment procedure: (dashed) weighting scheme by Sellers et al. (1996b) and (solid) weighting scheme applied in this study. 
3. For vegetation with a dormant and an active state in the vegetation phenology the weighted Fourier adjustment procedure is only applied to the growing season. The weighting scheme is modified as follows:

$$
\text { growing season: } \quad W=\left\{\begin{array}{l}
\left(\frac{(d-t)}{-t}\right)^{4}, t<d<0 \\
4 \sqrt{d}+1, d \geqslant 0
\end{array}\right.
$$

$$
\text { dormant period: } \quad W=1.0
$$

The non-weighted Fourier series $f$ is used during the dormant period and the weighted series during the growing season, thus both the weighted and the unweighted Fourier series are merged at the two phenological transition dates. This way the curve still inherits the seasonal periodicity of the growth cycle.

The Pathfinder NDVI dataset is processed by applying the steps 1-3 to the whole European domain, using data from August 1981 until July 2001. A yearly time-series over the Swiss Alps in figure 1 $(a)$ (thick solid line) shows that the beginning and the end of the growing season are identified precisely due to the high temporal resolution and the modified weighting scheme. In figure $1(b)$ an anomaly found at the end of the growing season in the original Pathfinder NDVI is eliminated by the spatial interpolation. There is an advantage in using separate corrections for the growing and the non-growing season, which can be seen in figure 1 $(c)$ : second-order Fourier series do not represent well growing seasons shorter than half a year (dashed line) and merging the separate corrections at the phenological transition dates (thick solid line) catches the onset and the offset of the growing season. In figure $1(d)$ a yearly time-series of an evergreen vegetation type mostly found in the northern European boreal zone is displayed and figure 1(e) shows evergreen vegetation in the north-western coast of France. A different seasonal behaviour with signs of dryness-related vegetation stresses is seen in figure $1(f)$ for southern European vegetation. However, not all time-series have been processed correctly: in figure $1(g)$ an unrealistic seasonal behaviour was created for a point in Ireland. Nevertheless the long and early growing season is a well known feature in Ireland, due to the influence of the NAD (North Atlantic Drift), and is represented well. In figure $1(h)$ an example is displayed where the growing season was not determined correctly.

The resulting dataset has been named EFAI-NDVI (European Fourier-Adjusted and Interpolated NDVI). It is a highly corrected dataset of European vegetation phenology covering the last two decades.

\subsection{Deriving biophysical parameters from the EFAI-NDVI}

Remotely sensed parameters like the EFAI-NDVI are not directly applicable in LSMs. The parameters needed by modern LSMs usually consist of a number of vegetation type-dependent static look-up values (like root depth or canopy height) and time-dependent parameters which describe the phenological evolution of the plants. Static parameter look-up tables by vegetation type can be found in the literature (Dickinson 1984, Sellers et al. 1996a,b) and will have a spatial distribution when combined with vegetation type maps (Hansen et al. 2000, Loveland et al. 2000). The most commonly used time-varying parameters include LAI, canopy greenness and $z_{0}$ (roughness length). More sophisticated models like SiB 2 make use of the FPAR parameter to scale leaf photosynthesis to the ecosystem level. 
We derive a number of biophysical land surface parameters from the previously generated EFAI-NDVI dataset. They include FPAR, LAI, $z_{0}$ and canopy greenness and are derived following the publication by Los (1998) by simple empirical relationships which have been verified and updated in various field observations (FIFE, OTTER, BOREAS and HAPEX-Sahel, see references in Los 1998, Los et al. 2000). The theoretical background to the derivation of these biophysical land surface parameters can be reviewed in Sellers et al. (1996b), Los (1998) and the most basic relationships are presented in the Appendix. Examples of these land surface parameters are shown in figures 5 and 6 .

In figure 5, a justification for the high temporal resolution of this dataset is found: the three maps show the LAI in the Alps region for the compositing periods of 1-10 May (a), 11-20 May (b) and 21-31 May (c). During this month a large increase in LAI is observed in southern Germany, eastern Austria but also in the alpine valleys of Switzerland. The use of monthly composites would mask many of these short term phenology changes.

In figure 6 the land surface parameters are illustrated for the time period of 10-21 July. FPAR has a very homogeneous pattern and shows high values over most of central, eastern and northern Europe during summer, where LAI exhibits a more spatially varying pattern, especially between tall forest vegetation and short groundcover in Scandinavia. A very dense vegetation with high LAI values is seen in most of eastern Europe. Roughness length has an exponential scaling with LAI and heavily depends on the canopy height. It clearly shows the distribution of short vegetation (low $z_{0}$ ranging from 5 to $20 \mathrm{~cm}$ ) and tall tree biomes (high $z_{0}$ between 1 and $3 \mathrm{~m}$ ).

\section{Spatial and temporal variability of European vegetation related to climate}

Spatial and temporal variability found in the land surface parameters is discussed in this section. We will mostly use the EFAI-NDVI as the primary parameter and not the derived land surface parameters. The derived land surface parameters inherit the same seasonal and interannual variability, since they are first-order dependent on the EFAI-NDVI and only second-order on land cover (see $\S 2)$. Statistics in this section are either calculated for the full Europe domain or for sub-domains. In figure 7 the geographical extents of the chosen sub-domains are illustrated. This sub-domain system does not reflect any bio-geographical stratification found in literature but is a first step to isolate and analyse the data by regional domains, also in view of the intended future applications of this dataset. It includes a longitudinal gradient from maritime (UK and Ireland) to continental (Western Russia) and a latitudinal gradient from the Alps to Northern Europe. The Mediterranean (e.g. Spain) is not included since the analysis procedure in this section requires a large seasonal amplitude in the phenology. The Alps are analysed separately since this area is of special interest for our research in regional climate.

\subsection{Seasonal variability}

Land surface vegetation is often classified into ecosystem types, the so-called biomes. Each such biome represents a community of plants in a certain climatic zone and can also be characterized by its specific phenological evolution throughout the year. Phenological events within a biome may include flowering, leafing, dryness-periods, harvesting (for agriculture biomes) and leaf-fall. The timing of 


\section{R. Stöckli and P. L. Vidale}
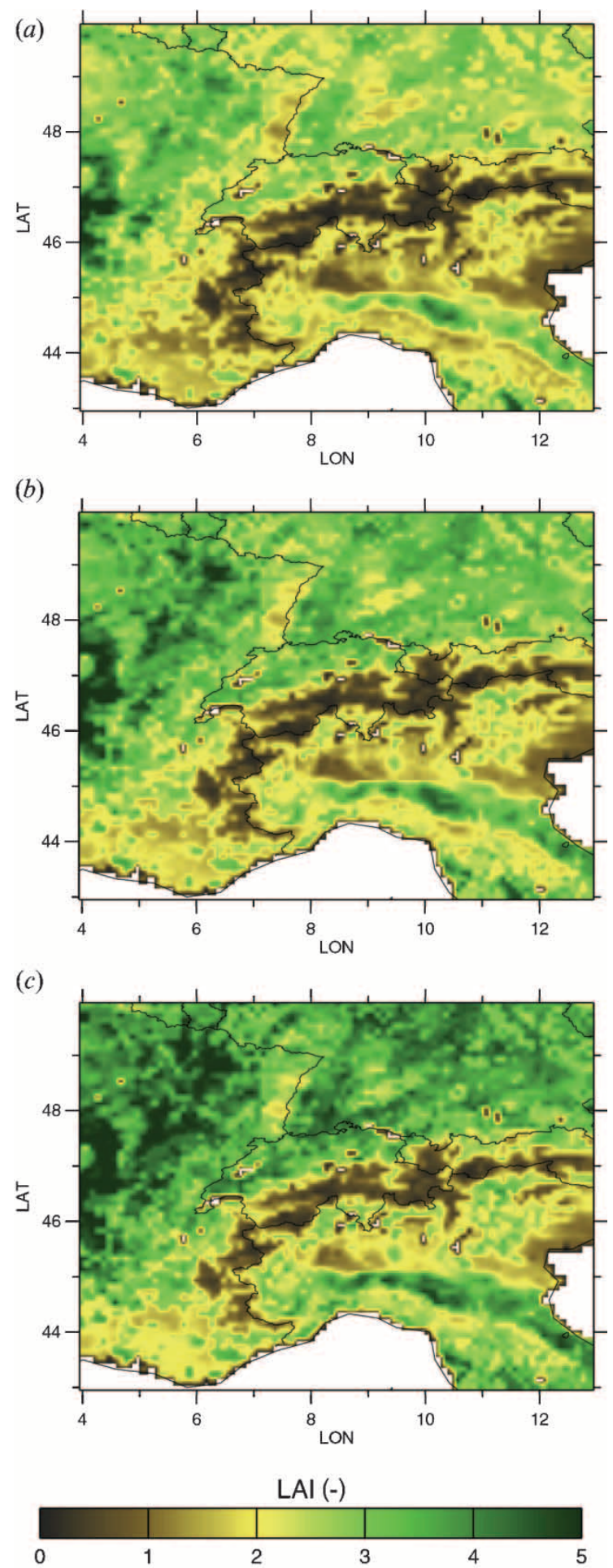

Figure 5. Time-series of LAI showing the need for high temporal coverage: Alpine spring greening for the (a) 1-10 May, (b) 11-20 May, (c) 21-31 May 1982-2001 composites. 
Plant phenology and climate from AVHRR data
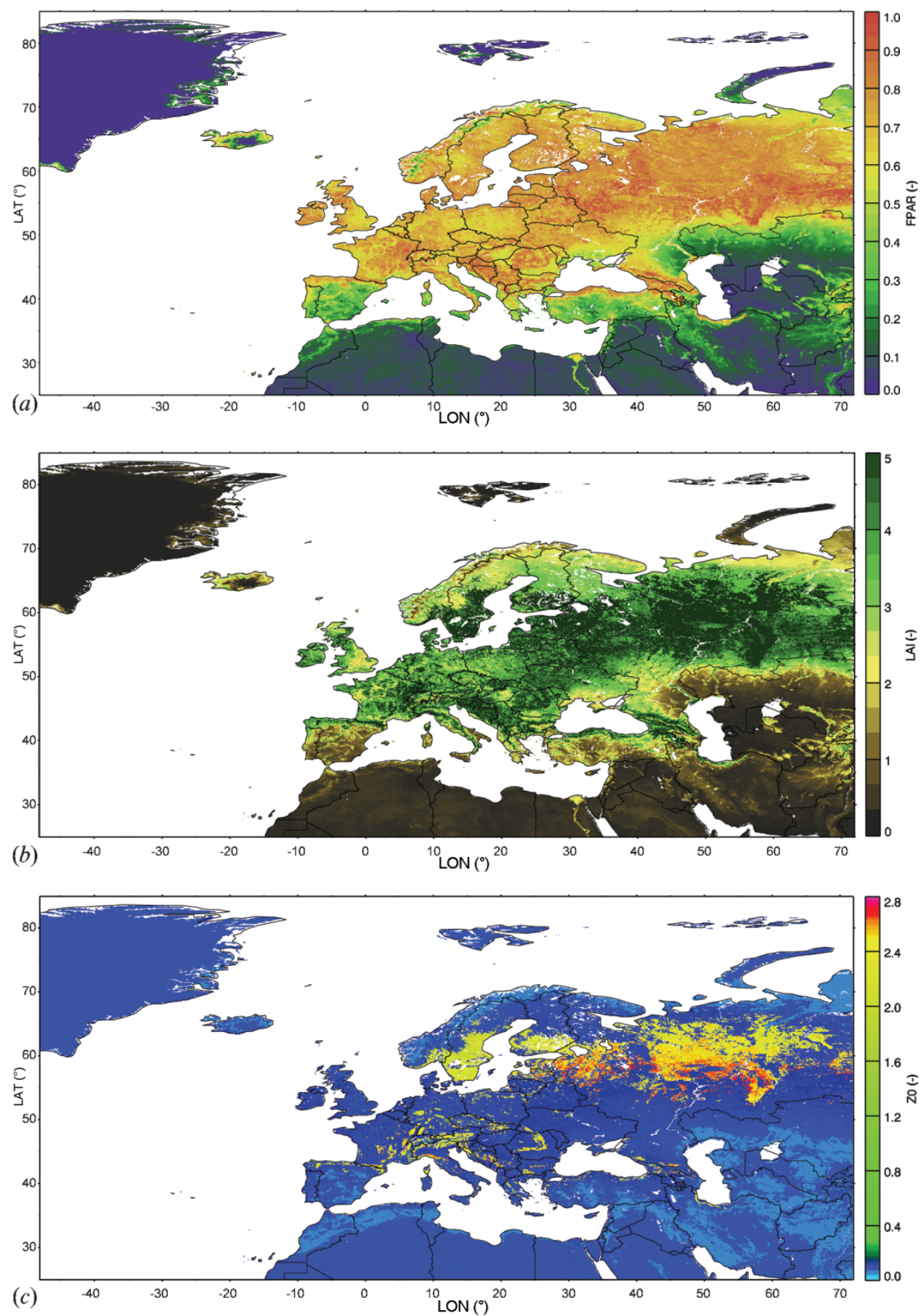

Figure 6. Maps of the derived land surface parameters covering the period from 10 to 21 July (average yearly climatology derived from the years 1982-2001). (a) FPAR, (b) LAI and $(c) z_{0}$.

these events is dependent on internal plant physiological factors and external influences like plant diseases and local climate.

In figure 8, phenological curves derived from the EFAI-NDVI and averaged by 


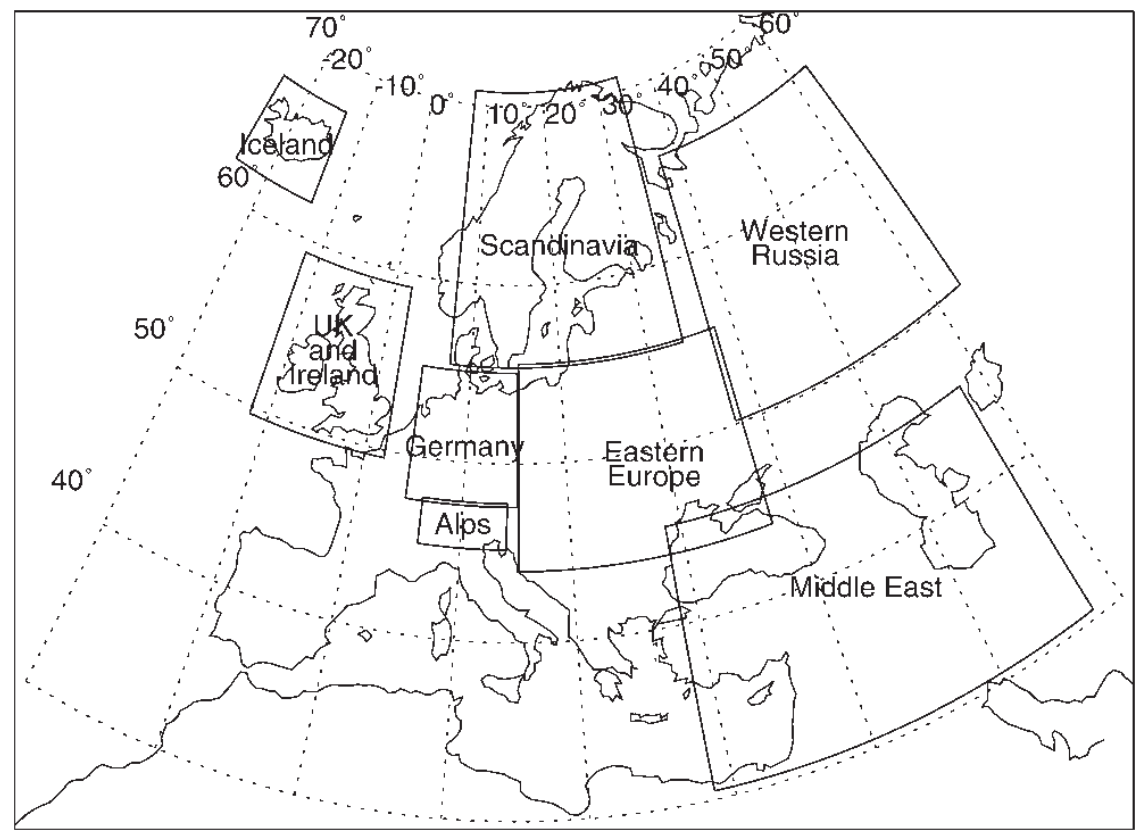

Figure 7. The sub-domain extents that were used to derive anomalies and trends in the EFAINDVI dataset.

land cover class ( $\mathrm{SiB}$ land cover classification, derived from the DeFries et al. 1998 land cover classification, see table A1) are shown on the left side. The distribution of NDVI values are displayed for each land cover class on the right side.

Deciduous forest types (figure $8(a),(b)$ and $(d)$ ) can clearly be distinguished from evergreen forest (figure $8(c)$ ) which is mostly found in the boreal zone and in alpine areas. In total, tall tree biomes account for $10.1 \%$ of the examined land surface. The evergreen pine trees keep their needles in winter and the seasonal variation is due to the deciduous plants found in those forests. Mixed and deciduous forests (figure $8(b)$ ) found in intermediate and high latitudes have a large seasonal variability, with low NDVI values in winter and high values in summer, also visible in the NDVI distribution diagrams (right column of figure 8).

The shrub and bare soil biome (figure $8(e)$ ) - covering $13.8 \%$ of the area-is found in the Mediterranean and is subject to a dry climate which does not allow the growth of tall trees. This fact is well reflected in the phenological curve of this biome, where even a reduced greenness in summer due to possible drought conditions is visible. Tundra vegetation (figure $8(f)$ ) is only present in $0.1 \%$ of the examined land surface area but the usually short vegetation period and low temperatures for this biome are reflected in the phenology curve, which does not reach high values even in July/August.

The soil/desert landcover class (figure $8(g)$ ) is not subject to much vegetation activity, as expected. A rapid and early increase in NDVI is seen in the agriculture

Figure 8. Yearly phenology time-series averaged by land cover class (left) and distributions of NDVI values for these curves (right). The time-series (solid lines) are plotted with their standard deviation (dashed lines) for each land cover class. 
Plant phenology and climate from AVHRR data
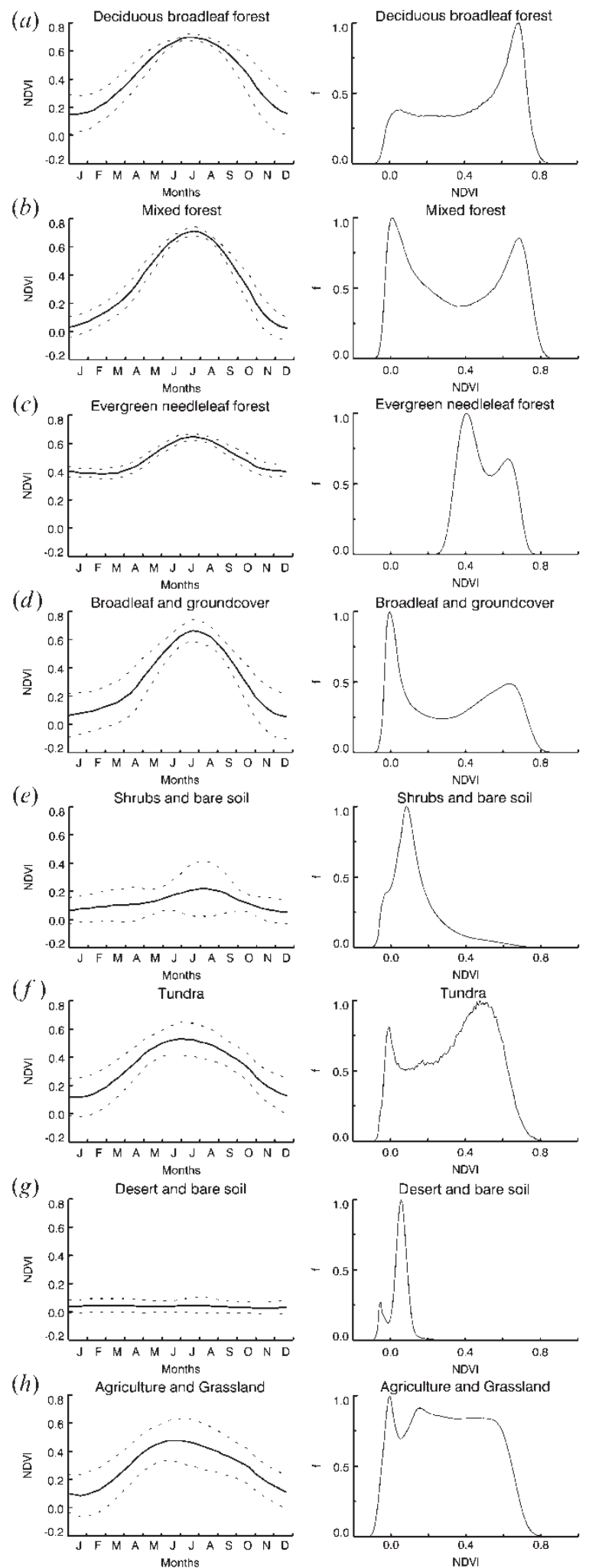
biome (figure $8(h)$ ) with a gradual decrease after June. Agricultural land is in fact the biome with the largest area coverage found in Europe (24.9\%)

\subsection{Interannual variability}

Remotely sensed data used in this study may not be able to fully describe the vegetation physiology of individual plants, because the data only reflect radiative properties of the canopy at a very coarse scale, but it is a good application to integrally measure the state of vegetation phenology at the ecosystem level. Used in this context, remotely sensed plant phenology is a very suitable proxy indicator of local and regional year-to-year climate variations. Yearly area averaged time-series of EFAI-NDVI over the Alps are plotted in figure 9.

This plot combines a representation of both the seasonal variability on the horizontal axis and of the interannual variability on the vertical axis (large temporal differences of up to a month in the onset and offset of the greening phase). To examine the interannual response of the satellite measured vegetation phenology to climate variability, yearly anomalies are calculated for three phenological metrics: spring date, growth period length and autumn date. These metrics (black dashed lines in figure 9) do not necessarily relate to point measurements of flowering and leaf-fall, but they provide a statistical means to exploit the interannual signal within the presented land surface parameter dataset.

For each grid point within the chosen sub-domains the phenological spring and autumn dates are determined by selecting the 10-day interval, where a certain threshold (here set to $\left.0.4\left(\mathrm{NDVI}_{\max }-\mathrm{NDVI}_{\min }\right)+\mathrm{NDVI}_{\min }\right)$ is crossed. In figure 9 the mean start and the end of the growing season over the 20 years for the Alps sub-domain is drawn as a dashed black line.

Using the spring and autumn date the vegetation growth period length is determined by subtracting the spring date from the autumn date. For each sub-domain,

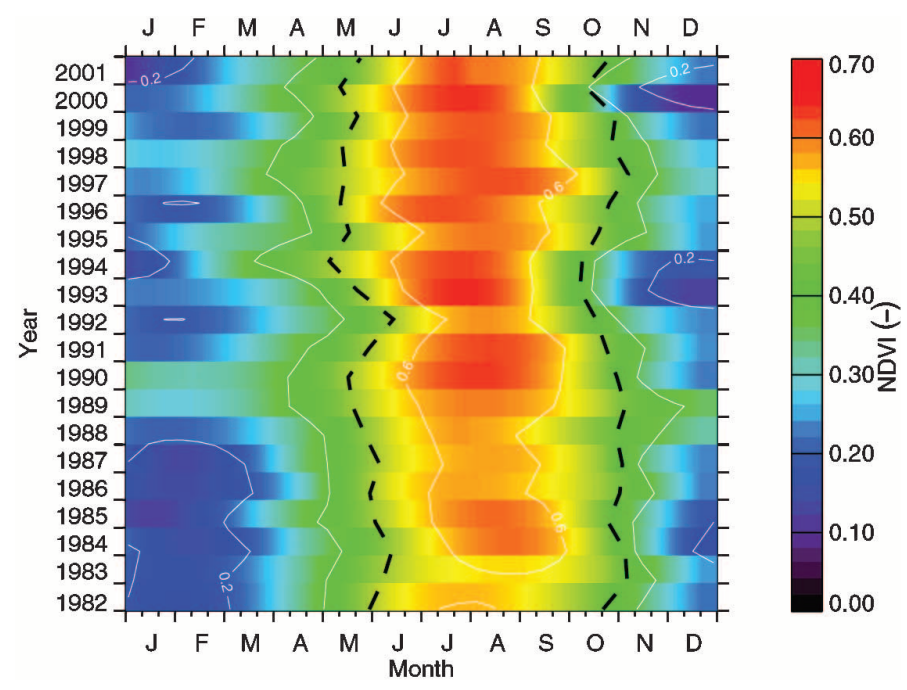

Figure 9. Interannual and seasonal variability as observed in the 20-year period from 1982 to 2001 for the Alps sub-domain. The area-averaged start and end of the growing season is plotted as a black dashed line. 
all successfully determined phenological metrics are averaged to form a regional scale time-series of spring dates, autumn dates and growth period lengths for the years 1982-2001.

In figure 10 the seasonal mean CRU (Climatic Research Unit) temperature and precipitation anomalies and the North Atlantic Oscillation (NAO) indices are plotted together with the phenological spring date anomalies for the individual years. For each
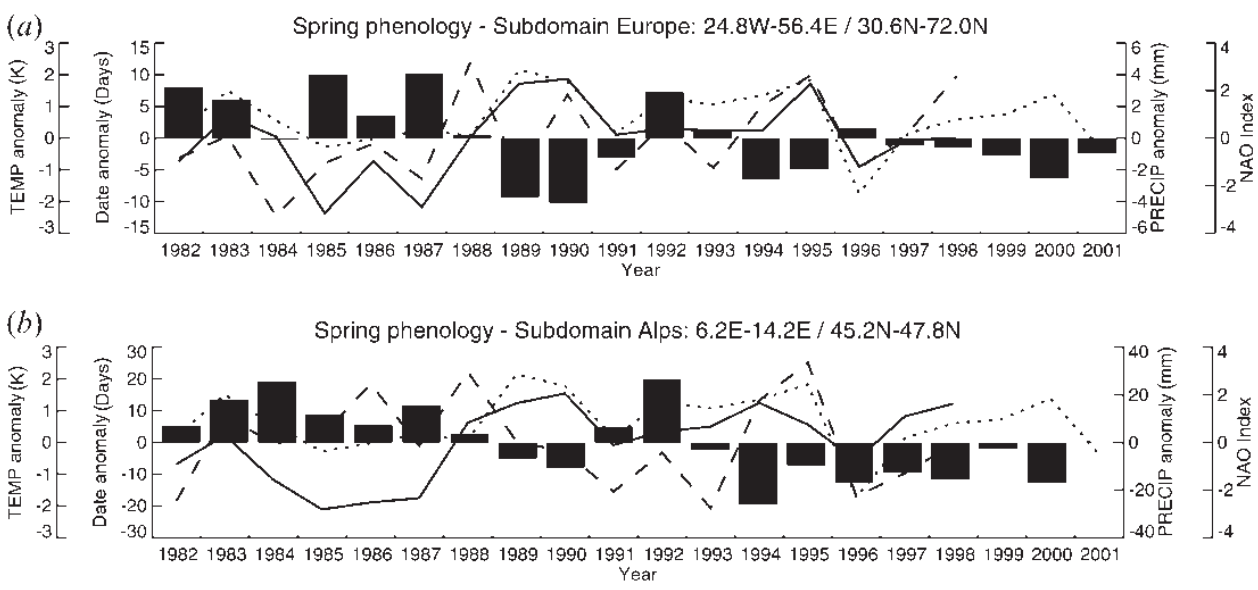

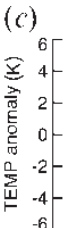
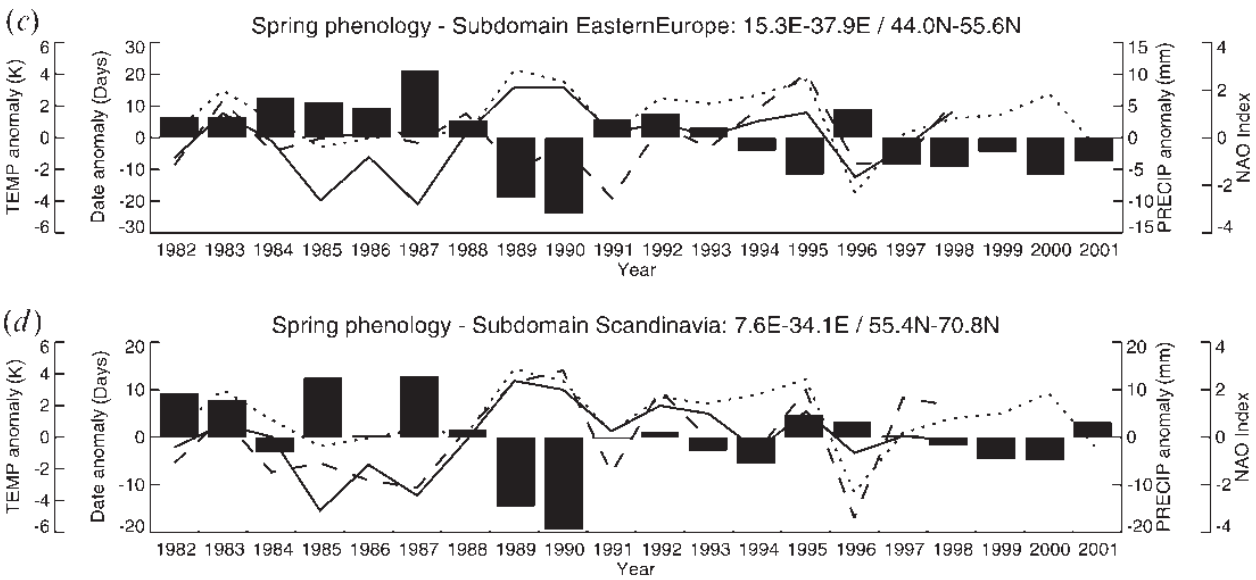

(c)

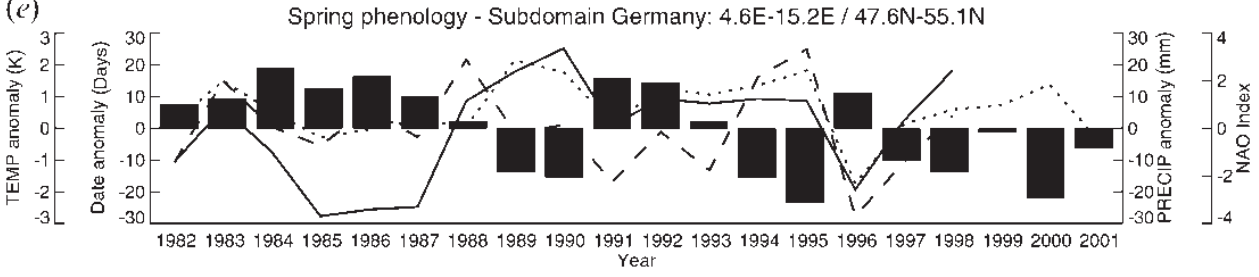

Figure 10. Yearly anomalies of spring dates (bars, negative values mean earlier springs) plotted with area averaged climate variables: CRU temperature (solid line; January, February, March, April average) and CRU precipitation (dashed line; January, February, March, April average) and the NAO index (dotted line; December, January, February, March average). The interannual variability in spring phenology is shown for the full domain Europe $(a)$ and for the sub-domains Alps (b), eastern Europe $(c)$, Scandinavia $(d)$ and Germany $(e)$. 
sub-domain the spring dates are compared with winter (January, February, March, April) temperature/precipitation anomalies and to the winter NAO indices (December, January, February, March). The NAO is a very relevant climatic index for Europe. Strong positive phases of the NAO tend to be associated with above-normal temperatures across Northern Europe and below-normal temperatures in Greenland and often across southern Europe and the Middle East. They are also associated with above-normal precipitation over northern Europe and Scandinavia and belownormal precipitation over southern and central Europe. Opposite patterns of temperature and precipitation anomalies are typically observed during strong negative phases of the NAO. The wintertime NAO, in particular, exhibits significant interannual and decadal variability (Hurrel 1995).

The full European domain (figure 10(a)) was subject to early springs in the years 1989 and 1990 as well as the years 1994 and 1995 and 2000. A positive winter NAO phase and warmer spring temperatures in 1989/1990 and in 1994/1995 are a possible indication of the continental scale climate influence on the observed greening pattern. The early 1980s were generally late years in phenological terms. Lower winter temperatures as well as a negative NAO index (normally leading to colder winters and springs and also to extended snow cover) can have caused delayed spring greenings of land surface vegetation during the period 1982-1987. In figure 11, phenological anomalies are correlated with climatic anomalies. The top row of figure 11 displays anomalies in spring phenology correlated to temperature, precipitation and NAO index anomalies. For Europe, winter temperatures are negatively correlated with the timing of plant-growth in spring (figure 11(a)). No significant correlation with precipitation is found (figure $11(b)$ ) but the winter $\mathrm{NAO}$ - a proxy for the general weather pattern over continental Europe - is weakly linked to spring phenological timing (figure 11(c)). In elevated terrain and at high latitudes plant growth in spring is known to be temperature limited and-because of the high soil moisture availability — not highly dependent on precipitation. Spring events such as needle flush and leaf unfolding are found in biometeorology to be very sensitive to spring and winter temperatures (Farquhar et al. 1980, Post and Stenseth 1999, Menzel 2000, Defila 2001).

The Alps (figure 10(b)) do not show anomalously early springs in the years 1989/ 1990 and 1995. Over this sub-domain we generally find late springs in the 1980s and early springs in the 1990s. Apart from effects on plant growth related to topography, the southern and eastern ridge of the Alps are known to be strongly influenced by Mediterranean climate, which can lead to a significant difference in the plant phenology to the one observed in the northern ridge (Defila 2001) and may also explain some of the difference between the Alps and the rest of Europe. In the second row of figure 11, we correlate spring temperature anomalies with spring phenology for different sub-domains. The correlation of spring anomalies with the observed winter/spring temperatures for the Alps sub-domain (figure $11(d)$ ) is rather weak compared with, for example, eastern Europe (figure 11(e)) and Scandinavia (figure 11(f)).

Spring anomalies for eastern Europe are plotted in figure 10(c) and show very large interannual variability. No strong decadal pattern (1980/1990s) like in the Alps is observed but rather the years 1989/1990, 1994/1995 and the most recent years 1997-2001 are exhibiting very early springs of up to 25 days earlier than the mean spring date. The negative correlation of eastern European spring phenology with temperature anomalies is also high, with a value of 0.789 (figure 11(e)).

Phenology in the Scandinavian sub-domain (figure 10 $(d)$ ) has a temporal pattern 

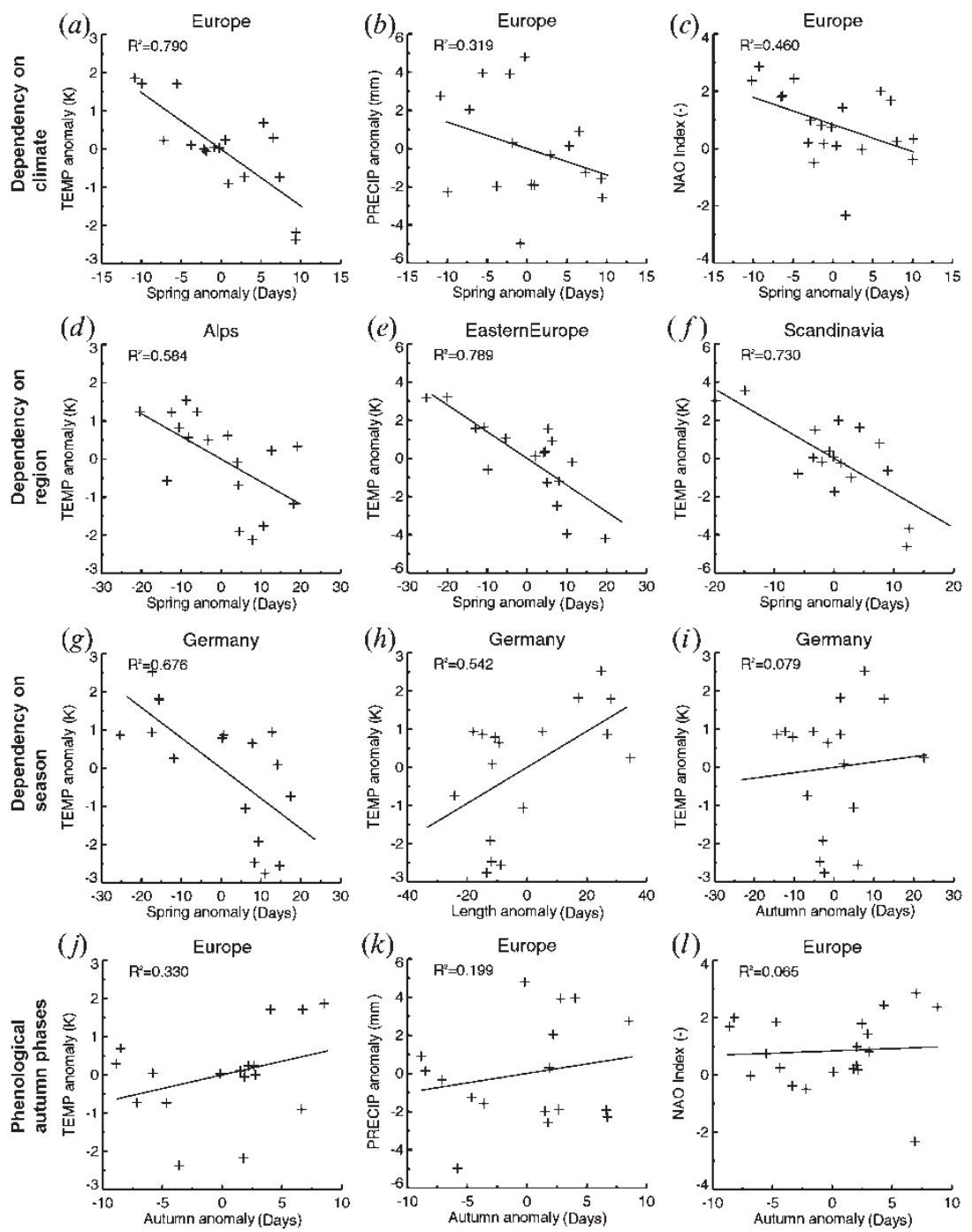

Figure 11. Phenological metrics (spring date, autumn date and vegetation period length) are correlated to temperature, precipitation and the NAO index in different sub-domains.

similar to the full European domain. The growing season had an exceptionally early start in the years 1989/1990 and did not show reasonable difference from the mean in the years 1994-1998. Generally, the decadal pattern of late springs in the 1980s is also visible in Scandinavia, but the same pattern is much more pronounced in western central Europe (figure 10(e)). Early leaf-out in Scandinavia is strongly linked with positive temperature deviations in winter/spring over that area (figure 11(f)).

Interannual variability of plant phenology is also observed on the ground in a sophisticated and long-term network of phenological gardens (IPG-International Phenological Gardens) around the globe. Menzel (2000) has collected and analysed observational data from the IPGs in Europe for the years 1959-1996. In this dataset the same years as observed in the EFAI-NDVI show an early spring with more 


\section{R. Stöckli and P. L. Vidale}

than a week difference compared with the 1976-1980 spring dates. The growing season was observed to be anomalously long throughout the period from 1989 until 1995, which was partly reproduced in this study. In our dataset the years 1989/1990 and 1994/1995 have early springs but years 1991-1993 show a rather nominal to late spring. It is well known in phenology research that the leaf-out in spring is easier to measure than the autumn date. In our dataset, autumn dates are likely to be affected by persistent cloud cover and data dropouts in winter. The third row of figure 11 correlates phenological metrics in different seasons to temperature anomalies. The autumn phases do not correlate well with spring temperatures (figure 11(i)). Also, summer temperature (figure 11 $(j)$ ), precipitation (figure 11 $(k)$ ) or NAO data (figure $11(l)$ ) anomalies are only correlating weakly with $R^{2}=0.330$, 0.199 and 0.065 . These simple relationships cannot account for the complex soilvegetation-atmosphere interactions during the summer months, especially for the long term soil-moisture memory related effects. For most sub-domains the growth period length has a positive (but weak) correlation with spring temperatures.

Since 1951, phenological data from wild grown plant species have been collected systematically in Switzerland. A number of plant species at different biogeographical locations are observed and phenological phases are recorded by lay observers and data are processed at MeteoSwiss. Defila $(1996,2001)$ has analysed the averaged time-series for spring and autumn events for Switzerland covering the years 1951-1995. Interannual variations of these observations show a good agreement with our phenology data. The overall picture of Switzerland indicates an exceptionally early spring in 1990 and 1994 (up to 20 days) and late growing seasons for the period 1985-1987. The metrics for the Alps and Germany (figure 10(b), (e)) show a similar temporal pattern, although the years 1989 and 1990 are somewhat less pronounced (4-7 days earlier spring) than in 1994 (20 days earlier).

\subsection{Multi-year trends}

Error sources in the remotely sensed NDVI products may be a serious limitation to the detection of anthropogenic trends in land surface vegetation. The nonadequate calibration of the used Pathfinder NDVI dataset described in $\$ 2$ can lead to errors of the same order of magnitude as the observed trends in NDVI. Also, existing satellite measurements cover a relatively short time period. It is important to keep these limitations in mind while working with trend analysis of NDVI timeseries. Satellite remote sensing is nevertheless the only feasible means that we have to observe the long term biospheric activity with a large area coverage.

In our dataset we assume that trends are due to changes in canopy reflectance properties, thus only occurring in vegetated areas. Trends detected in deserted areas can be attributed to systematic instrumental drifts. The mean EFAI-NDVI trend in a deserted region (Sahara $0.2^{\circ} \mathrm{E}-2.6^{\circ} \mathrm{E}, 29.3^{\circ} \mathrm{N}-31.1^{\circ} \mathrm{N}$ ) is $0.21 \%$ year $^{-1}$. Mean NDVI trends for vegetated areas are significantly higher and range from 0.9 to $1.5 \%$ year $^{-1}$, which supports the reliability of trends in vegetated areas.

We apply linear regression analysis to our NDVI time-series and check for trends in spring date, growth period length, autumn date, minimum NDVI, maximum NDVI and mean NDVI. Maps of Europe with spring and autumn date trends are shown in figure 12. The results reveal evidence for long-term changes in the European plant phenology. Central Europe seems to exhibit a general earlier appearance of plants in spring during the last 20 years, whereas northern Europe shows the opposite trend. 

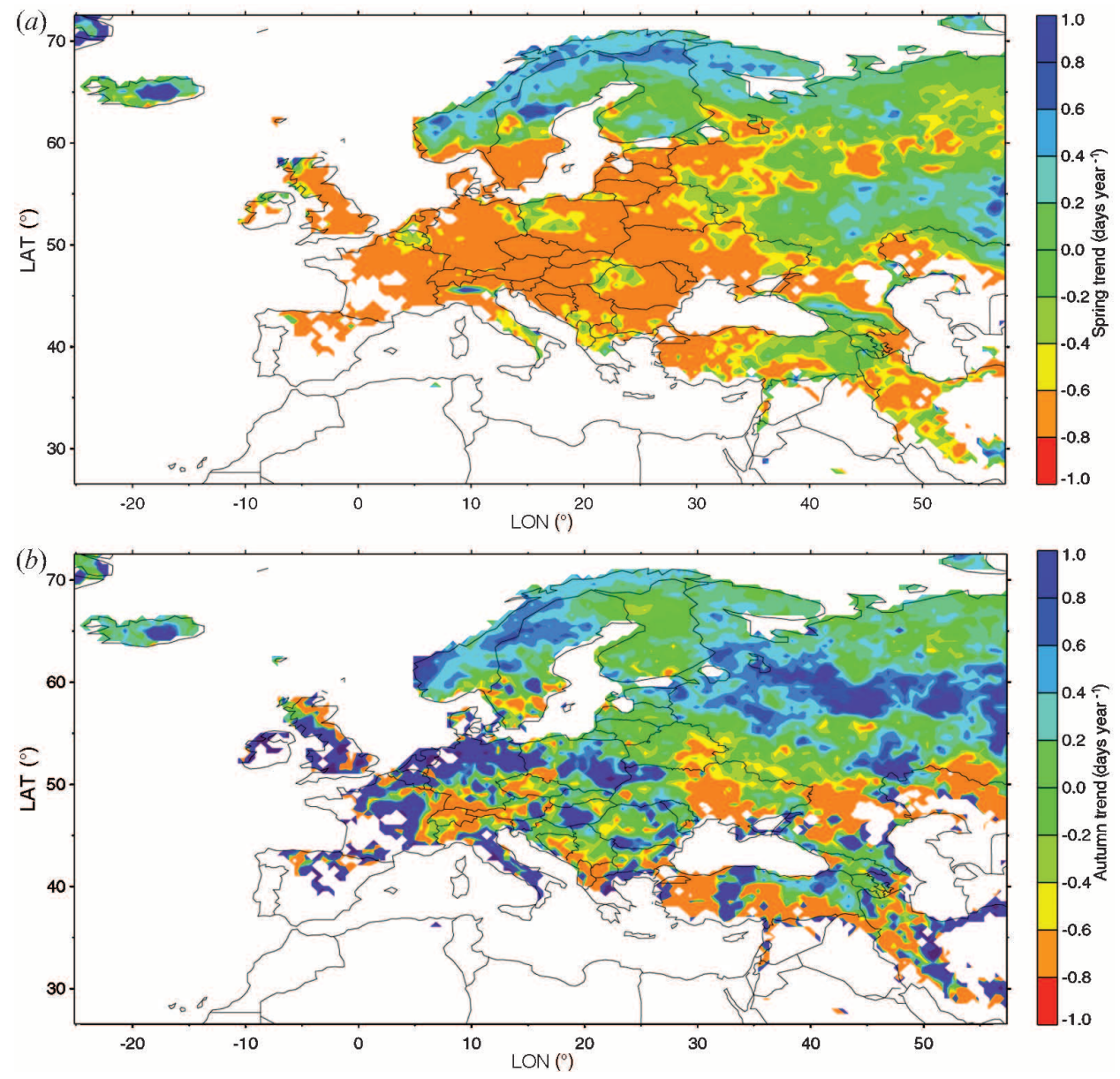

Figure 12. Multi-year trends found in the spring $(a)$ and the autumn dates $(b)$.

An average of the trends is calculated for the individual sub-domains in Europe. The trends of the phenological metrics are only calculated for grid points where a growth period was observed and phenological dates can actually be determined. In table 1, spring, autumn and growing season length trends given and classified

Table 1. Trends in European phenology derived from the EFAI-NDVI dataset.

\begin{tabular}{lcccc}
\hline Region & $\begin{array}{c}\text { Spring } \\
(\text { days year }\end{array}$ & $\begin{array}{c}\text { Autumn } \\
\left(\text { days year }^{-1}\right)\end{array}$ & $\begin{array}{c}\text { Length }^{-1} \\
\left(\text { days year }^{-1}\right)\end{array}$ & $\begin{array}{c}\text { NDVI } \\
\left(\% \text { year }^{-1}\right)\end{array}$ \\
\hline Germany & $-1.41 \dagger$ & $-0.04^{*}$ & $1.38 \dagger$ & 0.85 \\
Alps & -1.53 & $-0.69^{*}$ & $0.84^{*}$ & 0.74 \\
Scandinavia & $-0.48^{*}$ & $0.44^{*}$ & $0.92^{*}$ & 0.82 \\
Eastern Europe & $-1.32 \dagger$ & $0.30^{*}$ & $1.63^{*}$ & 1.12 \\
Western Russia & $-0.47^{*}$ & $0.61^{*}$ & $1.08^{*}$ & 0.79 \\
UK and Ireland & $-1.88 \dagger$ & $0.51^{*}$ & $2.38^{*}$ & 0.84 \\
Iceland & $-0.44^{*}$ & $0.37^{*}$ & $0.81^{*}$ & 1.26 \\
Middle East & $-0.48^{*}$ & $0.49^{*}$ & $0.97^{*}$ & 0.72 \\
Europe (full domain) & $-0.54^{*}$ & $0.42^{*}$ & $0.96 \dagger$ & 0.78 \\
\hline
\end{tabular}

Significance level: $* 1 \%, \pitchfork 5 \%, \ddagger 10 \%$. 
according to their $F$-test confidence values. The trend for the mean NDVI values found in each region is indicated in the last column.

Almost all trends are negative for spring dates and positive for autumn dates, thus a lengthening of the growing season is observed on a large area over the European continent. Certain areas like southern Germany and the Alps in particular are experiencing autumn phases occurring earlier (figure 12(b)).

Previous NDVI trend analysis like the one conducted by Myneni et al. (1997) only cover the period from 1981 to 1991 . We have analysed trends within this period and have found that they are remarkably higher with a mean NDVI trend of $2.26 \%$ year $^{-1}$ during the 1980 s and lower with $0.16 \%$ year $^{-1}$ in the 1990 s, resulting in a mean NDVI trend of $0.78 \%$ year $^{-1}$ for the whole period. Spring dates in this study show the same decadal variations, with a highly negative trend during the 1980s and almost no trends in the 1990s. The separate analysis of trends for the two decades suggests that the time-series is a product of long term regionally and globally changing vegetation phenology and periodic fluctuations. Both seem to be of the same order of magnitude.

\section{Discussion and conclusion}

In this study we compare satellite-derived phenology with ground-observed phenological data and correlate interannual variations of spring phenology to winter/spring temperature precipitation and NAO index anomalies. The original satellite sensor data used for this study are known to be subject to a number of potential problems. We have presented a means to effectively derive a consistent time-series of vegetation phenology by post-processing the Pathfinder NDVI with weighted second-order Fourier series.

One common problem reported in the literature is the question of whether the sudden increase of NDVI in spring at high latitudes coincides with snowmelt or is really the emergence of leaves (Reed et al. 1994). If the two events occur at significantly different times, then the beginning of the growing season derived from NDVI may just catch snowmelt-which is definitely not desired. In land surface models this error will not necessarily transfer to excessive plant activity due to temperature limitations and the explicit simulation of snow cover, but this problem may affect greening season length estimates.

Another weakness of satellite radiometry in visible wavelengths is the extended data dropouts in high latitudes during winter. The correction method used here is able to recover a continuous dropout of around 2 months and assumptions are made to estimate NDVI values for longer data dropouts. Sudden data dropouts in autumn may nevertheless limit the estimation of the growth period length in our phenological analysis. Apart from the uncertainty associated with remote sensing, the length of the growing period and the phenological autumn phases also cannot be simply linked to temperature and precipitation averages.

The onset of greening in spring varies for \pm 20 days relative to the mean date within this 20-year period. In general, 1985-1987 had late springs and years 1989, 1990, 1994 and 1995 had early ones. Large year-to-year fluctuations in the atmospheric $\mathrm{CO}_{2}$ signal have been observed by Keeling et al. (1996). Earlier starts of $\mathrm{CO}_{2}$ uptake by northern hemisphere vegetation are observed in Point Barrow for the years 1981, 1990 and 1991 and are nominal for the years 1984-1986; in contrast, the Mauna Loa record shows very early springs in the years 1987 and 1991-1992. Due to long-term soil respiration processes, a phase lag of 2 years between 
atmospheric $\mathrm{CO}_{2}$ anomalies and vegetation-climate anomalies is proposed by Keeling et al. (1996), which makes their results consistent with our analysis.

The knowledge of these interactions has led to the assumption that global land use changes, anthropogenic emissions of greenhouse gases $\left(\mathrm{CO}_{2}\right.$, methane) as well as the observed global warming are possibly enhancing large area biospheric activity. We find trends in the 20-year EFAI-NDVI that generally agree with recent findings in plant phenology research. Linear trends of the averaged EFAI-NDVI time-series vary from 0.72 to $1.12 \%$ per year depending on the region. These trends indicate an overall enhanced vegetation activity, mostly due to a prolongation of the growing season with earlier occurring springs for the whole Europe $\left(-0.54\right.$ days year $\left.^{-1}\right)$. Regional differences are visible. The trends are more pronounced in Germany (1.41 days year $\left.{ }^{-1}\right)$ than they are in Scandinavia $\left(-0.48\right.$ days year $\left.{ }^{-1}\right)$ where we also find evidence for delayed springs. The quantitatively small trends which are extracted from the satellite-measured vegetation phenology are, however, approximately of the same order of magnitude as the expected errors in the dataset. Moreover, the methodology presented here cannot replace and, in fact, requires a good precalibration of satellite sensor data, which is not available in the Pathfinder dataset. We believe that further research, longer NDVI time-series, ground validation and especially an in-depth cross-calibration with new satellite sensors (the MODIS instrument onboard TERRA and AQUA), and long-term ground measurements of phenological data are needed to gain more confidence.

Developing this methodology was useful in order to prepare for the arrival of MODIS data. The dataset has shown to be useful at this resolution and does agree with known European climatic zone characteristics in both space and time. Generally, the results increase our confidence in the usefulness of satellite sensor derived land surface parameters for land surface modelling. These parameters inherit seasonal and interannual dynamics seen in land surface vegetation over the last two decades. They are a good estimator for large-scale plant photosynthesis and phenology but they cannot account for many of the factors that drive land surface processes (such as soil moisture availability, nutrients availability and vapour pressure deficit). Only the use of these land surface parameters in a land surface model which is coupled to a climate model (e.g. the CHRM regional climate model, Vidale et al. 2003) will enable us to study the full spectrum of the complex soil-vegetation processes and land-atmosphere feedbacks. An upcoming paper will explore the application of this dataset in regional climate modelling.

\section{Acknowledgments}

The funding for this study was provided by the National Centre of Competence in Research on climate variability, predictability, and climate risks (NCCR) funded by the Swiss National Science Foundation (NSF). The authors would like to first express their thanks for the support and suggestions of Professor Christoph Schär.

We would like to thank Sietse O. Los, Jim Collatz and Jim Tucker for discussions and data and would like to acknowledge ETH and Code 912/913 at Goddard Space Flight Center for being able to use their computing resources, which were essential for the successful completion of this project. Special thanks go to Scott Denning, Kevin Schaefer and Ian Baker from CSU for providing access to the mapper code used to process the derived biophysical land surface parameters.

The Land Pathfinder NDVI data used in this study were produced through 


\section{R. Stöckli and P. L. Vidale}

funding from the Earth Observing System Pathfinder Program of NASA's Mission to Planet Earth in cooperation with the National Oceanic and Atmospheric Administration. The data were provided by the Earth Observing System Data and Information System (EOSDIS), Distributed Active Archive Center at Goddard Space Flight Center, which archives, manages and distributes this dataset.

We highly encourage the use of the presented biophysical land surface parameters as a climatology (1982-2001) or as a 20-year time-series. This dataset is designed for and capable of enhancing existing LSMs with a boundary condition allowing the representation of spatial and temporal dynamics of land surface vegetation. The parameter set is available from the authors upon request.

\section{Appendix}

The basic relationships between NDVI and the most common land surface parameters are reviewed in this section.

Dye and Goward (1993) and Sellers et al. (1996b) show that FPAR has a linear relationship with NDVI:

$$
\mathrm{FPAR}=\frac{\left(\mathrm{NDVI}-\mathrm{NDVI}_{\min }\right)}{\left(\mathrm{NDVI}_{\max }-\mathrm{NDVI}_{\min }\right)}\left(\mathrm{FPAR}_{\max }-\mathrm{FPAR}_{\min }\right)+\mathrm{FPAR}_{\min }
$$

where $\mathrm{NDVI}_{\min }=2 \% \mathrm{NDVI}$ value of the NDVI distribution in a land cover class, see table A1; NDVI $_{\max }=98 \%$ NDVI value of the NDVI distribution in a land cover class, see table A1; FPAR $=$ Fraction of Photosynthetically Active Radiation absorbed by the green leaves of the canopy; $\mathrm{FPAR}_{\max }=0.95$; and $\mathrm{FPAR}_{\min }=0.01$.

Los et al. (2000) also use the RVI-FPAR relationship, where RVI (Ratio

Table A1. DeFries et al. (1998) - SiB land cover reclassification with NDVI-FPAR scaling values.

\begin{tabular}{|c|c|c|c|c|c|c|c|c|}
\hline $\begin{array}{l}\text { Class } \\
\mathrm{SiB}\end{array}$ & $\begin{array}{l}\text { Class } \\
\text { UMD }\end{array}$ & $\begin{array}{c}\text { Dominant vegetation } \\
\text { type }\end{array}$ & $\begin{array}{c}\% \\
\text { Cover }\end{array}$ & $\mathrm{NDVI}_{\min }$ & $\mathrm{NDVI}_{\max }$ & $\mathrm{LAI}_{\max }$ & LAIs & $\begin{array}{l}z_{2} \\
(\mathrm{~m})\end{array}$ \\
\hline 0 & 0 & Ocean and inland water & - & - & - & - & - & - \\
\hline 1 & 2 & Broadle & - & - & - & 7 & .08 & 35.0 \\
\hline 2 & 4 & Broadleaf deciduous trees & 0.4 & 0.008 & 0.766 & 7 & .08 & 20.0 \\
\hline 3 & 5 & $\begin{array}{l}\text { Broadleaf and needleleaf } \\
\text { trees }\end{array}$ & 4.4 & -0.015 & & 7.5 & 0.08 & 20.0 \\
\hline 4 & 1 & Needleleaf evergreen trees & 5.3 & -0.102 & & 8 & 0.08 & 17.0 \\
\hline 5 & 3 & $\mathrm{~N}$ & & -0 . & & 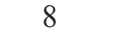 & 08 & 17.0 \\
\hline 6 & 6 & Broac & & $-0 .($ & & 3 & .05 & 1.0 \\
\hline 7 & 7 & Grassland and shrub cover & 9.3 & -0.055 & 0.718 & se & 0.05 & 1.0 \\
\hline 8 & - & Shrubs and gi & - & - & - & 5 & 0.05 & 1.0 \\
\hline 9 & 8,9 & $\begin{array}{l}\text { Broadleaf shrubs with bare } \\
\text { soil }\end{array}$ & 13.8 & $-0.039^{*}$ & $0.695^{*}$ & 5 & 0.05 & 0.5 \\
\hline 10 & 13 & Tundra & & & & & & 0.6 \\
\hline 11 & 12 & & 21.3 & & & & & 1.0 \\
\hline 12 & 10,11 & Agriculture and grasslands & 24.9 & -0.0 & & 6 & 0.05 & 1.0 \\
\hline 13 & - & Ice & 12.9 & $-0.039 *$ & $0.695^{*}$ & 5 & 0.01 & - \\
\hline
\end{tabular}

*These values were taken from the SiB Grassland class, since NDVI for these vegetation types does not rise to a maximum FPAR.

$\dagger$ There are no broadleaf evergreen trees (tropical rainforest) in the processed European domain.

$\$$ For this $\mathrm{SiB}$ land cover class, no appropriate UMD class is found.

$\S$ The Ice class was merged from the FAO Digital Soil Map of the World (FAO 1995). 
Vegetation Index; see, for example, Tucker 1979) is the ratio of the NIR and VIS reflectances:

$$
\begin{gathered}
\mathrm{RVI}=\frac{\mathrm{NIR}}{\mathrm{VIS}}=\frac{1+\mathrm{NDVI}}{1-\mathrm{NDVI}} \\
\mathrm{FPAR}=\frac{\left(\mathrm{RVI}-\mathrm{RVI}_{\min }\right)}{\left(\mathrm{RVI}_{\max }-\mathrm{RVI}_{\min }\right)}\left(\mathrm{FPAR}_{\max }-\mathrm{FPAR}_{\min }\right)+\mathrm{FPAR}_{\min }
\end{gathered}
$$

where $\mathrm{RVI}_{\min }=2 \% \mathrm{RVI}$ value of the RVI distribution in a land cover class, see table $\mathrm{A} 1$; and $\mathrm{RVI}_{\max }=98 \% \mathrm{SR}$ value of the RVI distribution in a land cover class, see table A1.

In both models the FPAR values are scaled using a linear scaling factor within the observed EFAI-NDVI range for each land cover class. The observed EFAINDVI range for each land cover class $(2 \%$ and $98 \%$ values of the NDVI distributions) is documented in table A1. The recently published Hansen et al. (2000) $1 \mathrm{~km}$ global land cover classification is spatially resampled to $0.1^{\circ} \times 0.1^{\circ}$ and the 13 UMD (University of Maryland) land cover classes are translated into the $12 \mathrm{SiB}$ land cover classes. The ice/glacier class is merged from the FAO soil distribution map. Following Los et al. (2000), the average of the two FPAR scaling methods is used.

For each grid cell, the vegetation cover fraction (vcf, time invariant) is determined:

$$
\mathrm{vcf}=\max (\text { FPAR }) / \text { FPAR }_{\max }
$$

LAIg (leaf area index of the green portion of the canopy) can be derived from FPAR by a logarithmic relationship (Tucker and Sellers 1986, Baret and Guyot 1991, Sellers et al. 1996b):

$$
\mathrm{LAIg}=\frac{\log \left(1-\frac{(\text { FPAR })}{\mathrm{vcf}}\right) \mathrm{LAIg}_{\max }}{\log \left(1-\mathrm{FPAR}_{\max }\right)} \mathrm{vef}
$$

where $\mathrm{LAIg}_{\max }=$ maximum allowed LAIg for each land cover class, see table A1; and LAIg = leaf area index for the green part of the vegetation.

The total LAI for a grid cell is then the sum of the green, the stem and the dead LAI (LAIg, LAIs, LAId) multiplied by the vegetation cover fraction:

$$
\mathrm{LAI}=\mathrm{LAIg}+\mathrm{LAIs}+\mathrm{LAId}
$$

where LAId $=$ dead leaf area index (dead leaves within a grid cell) and LAIs $=$ stem area index by land cover class, see table A1. When LAI increases during the growing period, LAId has a minimum value of 0.0001. As soon as LAI begins to decrease, LAId is set to half of the LAI decrease between two time-steps.

The canopy greenness GREEN is simply calculated by the time-dependent evolution of the total LAI:

$$
\text { GREEN }=\text { LAIg/LAI }
$$

Studies show that there exists an exponential relationship between the LAI and $z_{0}$ (canopy roughness length), which leads to the empirical formulation (also found in Los 1998):

$$
z_{0}=z_{2}\left(1-a \mathrm{e}^{-b \mathrm{LAI}}\right)
$$

where $z_{2}=$ canopy height, by vegetation type, see table A1; $a=0.91$; and $b=0.0075$. 


\section{References}

Asrar, G., Kanemasu, E. T., Jackson, R. D., and Pinter, P. J., 1985, Estimation of total above-ground phytomass production using remotely sensed data. Remote Sensing of Environment, 17, 211-220.

BAret, F., and GuYOT, G., 1991, Potentials and limits of vegetation indexes for LAI and APAR assessment. Remote Sensing of Environment, 35, 161-173.

BETTS, A. K., and BALL, J. H., 1997, Albedo over the boreal forest. Journal of Geophysical Research, 102, 28 901-28909.

BonAN, G. B., 1996, A land surface model (LSM version 1.0) for ecological, hydrological, and atmospheric studies: technical description and user's guide. NCAR Technical Note, NCAR/TN-417+STR, National Center for Atmospheric Research, Boulder, Colorado.

Bounoua, L., Collatz, G. J., Sellers, P. J., Randall, D. A., Dazlich, D. A., Los, S. O., Berry, J. A., Fung, I., Tucker, C. J., Field, C. B., and Jensen, T. G., 1999, Interactions between vegetation and climate: radiative and physiological effects of doubled atmospheric $\mathrm{CO}_{2}$. Journal of Climate, 12, 309-324.

Champeaux, J.-L., Arcos, D., Bazile, E., Giard, D., Goutorbe, J.-P., Habets, F., NoIlHan, J., and RouJEAN, J.-L., 2000, AVHRR-derived vegetation mapping over Western Europe for use in numerical weather prediction models. International Journal of Remote Sensing, 21, 1183-1199.

Chen, F., Pielke, R. A., and Mitchell, K., 2001, Development and application of landsurface models for mesoscale atmospheric models: problems and promises. Water Science and Application, 3, 107-135.

Cihlar, J., MANAK, D., and VoISIN, N., 1994, AVHRR bidirectional reflectance effects and compositing. Remote Sensing of Environment, 48, 77-88.

DefiLA, C., 1996, 45 years phytophenological observations in Switzerland, 1951-1995. Proceedings of 14th International Congress of Biometeorology 1-8 September 1996, Ljubljana, Slovenia, edited by A. Hoèevar, Z. Repinèek and L. Kajfe-Bogataj, Biometeorology, Volume 14, pp. 175-183.

DefilA, C., 2001, Phytophenological trends in Switzerland. International Journal of Biometeorology, 45, 203-207.

DeFries, R. S., Hansen, M., Townshend, J. R. G., and Solberg, R., 1998, Global land cover classification at $8 \mathrm{~km}$ spatial resolution: the use of training data derived from Landsat imagery in decision tree classifiers. International Journal of Remote Sensing, 19, 3141-3168.

DiCKInSON, R. E., 1984, Modelling evapotranspiration for three-dimensional global climate models. In Climate Processes and Climate Sensitivity, edited by J. E. Hansen and T. Takehashi, (Washington, DC: American Geophysical Union), 29, pp. 58-72.

Dye, D. G., and Goward, S. N., 1993, Photosynthetically active radiation absorbed by global land vegetation in August 1984. International Journal of Remote Sensing, 14, 3361-3364.

Farquhar, G. D., Caemmerer, S. V., and Berry, J. A., 1980, A biochemical model of photosynthetic $\mathrm{CO}_{2}$ assimilation in leaves of $\mathrm{C} 3$ species. Planta, 149, 78-90.

FAO (Food and Agriculture Organization), 1995, A Digital Soil Map of the World. CD-ROM, Land and Water Development Division, FAO, Rome, Italy.

Gordon, H. R., BROWN, J. W., and EvANS, R. H., 1988, Exact Rayleigh scattering calculations for use with the Nimbus-7 coastal zone color scanner. Applied Optics, 27, 2111-2122.

Goward, S. N., Markham, B., Dye, D. G., Dulaney, W., and Yang, J., 1991, Normalized Difference Vegetation Index measurements from the Advanced Very High Resolution Radiometer. Remote Sensing of Environment, 35, 257-277.

Gutman, G. G., and IgnAtov, A., 1995, Global land monitoring from AVHRR: potentials and limitations. International Journal of Remote Sensing, 16, 2301-2309.

Hansen, M. C., DeFries, R. S., Townshend, J. R. G., and Sohlberg, R., 2000, Global Land cover classification at $1 \mathrm{~km}$ spatial resolution using a classification tree approach. International Journal of Remote Sensing, 21, 1331-1364.

Holben, B. N., 1986, Characteristics of maximum-value composite images for temporal AVHRR data. International Journal of Remote Sensing, 7, 1435-1445.

Hurrel, J. W., 1995, Decadal trends in the NAO. Science, 269, 676-679.

James, M. E., and Kalluri, S. N. V., 1994, The Pathfinder AVHRR land dataset: an 
improved coarse resolution dataset for terrestrial monitoring. International Journal of Remote Sensing, 15, 3347-3363.

Justice, C. O., Townshend, J. R. G., Holben, B. N., and Tucker, C. J., 1985, The phenology of global vegetation using meteorological satellite data. International Journal of Remote Sensing, 6, 1271-1318.

Keeling, C. D., Chin, J. F. S., and Whorf, T. P., 1996, Increased activity of northern vegetation inferred from atmospheric $\mathrm{CO}_{2}$ measurements. Nature, 382, 146-149.

Los, S. O., 1998, Linkages between global vegetation and climate: an analysis based on NOAA-Advanced Very High Resolution Radiometer Data. PhD Dissertation, Vrije Universiteit, Amsterdam.

Los, S. O., Collatz, G. J., Sellers, P. J., Malmstrom, C. M., Pollack, N. H., DeFries, R. S., Bounoua, L., Parris, M. T., Tucker, C. J., and Dazlich, D. A., 2000, A global 9-year biophysical land surface dataset from NOAA AVHRR data. Journal of Hydrometeorology, 1, 183-199.

Los, S. O., Collatz, G. J., Bounoua, L., Sellers, P. J., and Tucker, C. J., 2001, Global interannual variations in sea surface temperature and land surface vegetation, air temperature, and precipitation. Journal of Climate, 14, 1535-1549.

Loveland, T. R., Reed, B. C., Brown, J. F., Ohlen, D. O., Zhu, Z., Yang, L., and Merchant, J. W., 2000, Development of a global land cover characteristics database and IGBP DISCover from $1 \mathrm{~km}$ AVHRR data. International Journal of Remote Sensing, 21, 1303-1330.

MANABE, S., 1969, Climate and the ocean circulation: 1 . The atmospheric circulation and the hydrology of the earth's surface. Monthly Weather Review, 97, 739-805.

MatThews, E., 1983, Global vegetation and land use: new high-resolution data bases for climate studies. Journal of Climate and Applied Meteorology, 22, 474- 487.

Meeson, B. W., Corprew, F. E., McManus, J. M. P., Myers, D. M., Closs, J. W., Sun, K.-J., Sunday, D. J., and Sellers, P. J., 1995, ISLSCP Initiative I: Global Data Sets for Land-Atmosphere Models, 1987-1988, vols 1-5. CD ROM, NASA Goddard DAAC, Greenbelt, USA.

Menzel, A., 2000, Trends in phenological phases in Europe between 1951 and 1996. International Journal of Biometeorology, 44, 76-81.

Moulin, S., Kergoat, L., Voivy, N., and Dedieu, G., 1997, Global-scale assessment of vegetation phenology using NOAA/AVHRR satellite measurements. Journal of Climate, 10, 1154-1170.

Myneni, R. B., Keeling, C. D., Tucker, C. J., Asrar, G., and Nemani, R. R., 1997, Increased plant growth in the northern high latitudes from 1981-1991. Nature, 386, 698-702.

PIELKE, R. A., 2001, Earth system modeling - an integrated assessment tool for environmental studies. In Present and Future of Modeling Global Environmental Change: Toward Integrated Modeling, edited by T. Matsuno and H. Kida (Tokyo: Terrapub), pp. 311-337.

Post, E., and Stenseth, N. C., 1999, Climatic variability, plant phenology, and northern ungulates. Ecology, 80, 1322-1339.

Rao, C. R., and Chen, J., 1996, Post-launch calibration of the visible and near-infrared channels of the Advanced Very High Resolution Radiometer on the NOAA-14 spacecraft. International Journal of Remote Sensing, 17, $2743-2847$.

Reed, B. C., Brown, J. F., Vanderzee, D., Loveland, T. R., Merchant, J. W., and OHLEN, D. O., 1994, Measuring phenological variability from satellite imagery. Journal of Vegetation Science, 5, 703-714.

Roetzer, T., Wittenzeller, M., Haeckel, H., and Nekovar, J., 2000, Phenology in central Europe - differences and trends of spring phenophases in urban and rural areas. International Journal of Biometeorology, 44, 60-66.

Sellers, P. J., Randall, D. A., Collatz, G. J., Berry, J. A., Field, C. B., Dazlich, D. A., ZhANG, C., and Bounoua, L., 1996a, A revised land surface parameterization (SiB2) for GCMs. Part 1: Model formulation. Journal of Climate, 9, 676-705.

Sellers, P. J., Los, S. O., Tucker, C. J., Justice, C. O., Dazlich, D. A., Collatz, G. J., and RANDALL, D. A., 1996b, A revised land surface parameterization (SiB2) for atmospheric GCMs. Part 2: The generation of global fields of terrestrial biophysical parameters from satellite data. Journal of Climate, 9, 706-737.

Sellers, P. J., Dickinson, R. E., Randall, D. A., Betts, A. K., Hall, F. G., Berry, 


\section{Plant phenology and climate from AVHRR data}

J. A., Collatz, G. J., Denning, A. S., Mooney, H. A., Nobre, C. A., Sato, N., Field, C. B., and Henderson-Sellers, A., 1997, Modeling the exchanges of energy, water, and carbon between continents and the atmosphere. Science, 275, 502-509.

TUCKER, C. J., 1979, Red and photographic infrared linear combinations for monitoring vegetation. Remote Sensing of Environment, 8, 127-150.

Tucker, C. J., and MAtson, M., 1985, Determination of volcanic dust deposition of El Chichon from ground and satellite data. International Journal of Remote Sensing, $\mathbf{6}$, 619-627.

Tucker, C. J., and Sellers, P. J., 1986, Satellite remote sensing of primary production. International Journal of Remote Sensing, 7, 1395-1416.

Vermote, E. F., El Saleous, N., Justice, C. O., Kaufman, Y. J., Privette, J. L., Remer, L., Roger, J. C., and TANre, D., 1997, Atmospheric correction of visible and middle-infrared EOS-MODIS data over land surfaces: background, operational algorithm and validatation. Journal of Geophysical Research, 102, 17131-17141.

Vidale, P. L., Luethi, D., Frei, C., Seneviratne, S., and Schaer, C., 2003, Predictability and uncertainity in a regional climate model. Journal of Geophysical Research, 108(D18), 4586.

VoIvy, N., and SAINT, G., 1994, Hidden Markov models applied to vegetation dynamics analysis using satellite remote sensing. IEEE Transactions on Geoscience and Remote Sensing, 32, 906-917.

Wilson, M. F., and Henderson-Sellers, A., 1985, A global archive of land cover and soils data for use in general circulation models. Journal of Climatology, 5, 119-143.

Zhou, L., Tucker, C. J., Kaufmann, R. K., Slayback, D., Shabanov, N. V., and MYNENI, R. B., 2001, Variations in northern vegetation activity inferred from satellite data of vegetation index during 1981 to 1999. Journal of Geophysical Research, 106, $20069-20083$. 